\title{
UTILIZAÇÃO DE MARCADOR MOLECULAR SCAR NA IDENTIFICAÇÃO DE Fusarium subglutinans, AGENTE CAUSAL DA MALFORMAÇÃO DA MANGUEIRA ${ }^{1}$
}

\author{
RONALDO POSELLA ZACCARO², LUCIA MARIA CARARETO-ALVES², REGIANE FÁTIMA TRAVENSOLO², \\ ESTER WICKERT ${ }^{2}$, ELIANA GERTRUDES MACEDO LEMOS ${ }^{3}$
}

RESUMO-O gênero Fusarium é responsável por doenças em diversas plantas economicamente importantes. Entre estas doenças, destaca-se a malformação da mangueira, causada pelo fungo Fusarium subglutinans. O objetivo deste trabalho foi desenvolver oligonucleotídeos iniciadores para reação em cadeia da polimerase (PCR), específicos para o fungo $F$. subglutinans da mangueira. A amplificação de DNA de oito Fusarium spp. de diferentes hospedeiros, usando o oligonucleotídeo randômico UBC-41 (TTAACCGGGG), produziu um fragmento de aproximadamente $1.300 \mathrm{pb}$ somente para o fungo da mangueira. Tendo em vista que padrões de bandeamento por RAPD não são considerados confiáveis devido à baixa reprodutibilidade dos resultados, o fragmento diferencial foi eluído do gel de agarose, purificado, clonado e seqüenciado. As seqüências nucleotídicas foram utilizadas para identificar e sintetizar quatro pares de oligonucleotídeos específicos, denominados Fs 5, Fs 13, Fs 14 e Fs 15. DNAs de Fusarium spp. de outros hospedeiros (alho, amendoim, cana-de-açúcar, ciclâmen, ervilha, melão e trigo), da planta de mangueira cv. Tommy Atkins sadia e de outros cinco isolados de F. subglutinans de mangueira sintomática, foram submetidos à amplificação com os pares de oligonucleotídeos. Fragmentos amplificados foram visualizados somente para F. subglutinans de mangueira, demonstrando assim a especificidade dos oligonucleotídeos SCAR desenhados.

Termos de Indexação: oligonucleotídeos iniciadores, Mangifera indica, marcadores moleculares, RAPD-PCR.

\section{USE OF MOLECULAR MARKER SCAR IN THE IDENTIFICATION OF Fusarium subglutinans, CAUSAL AGENT OF MANGO MALFORMATION}

\begin{abstract}
The Fusarium genus is responsible for serious diseases in many economically important crops. Among these diseases it is distinguished the mango flower malformation, caused by the fungus Fusarium subglutinans. The objective of this work was to develop specific oligonucleotide primers for the polymerase chain reaction (PCR) targeting the mango flower malformation by fungus $F$. subglutinans. The DNA amplification of eight Fusarium spp. collected from different hosts making the use of a random oligonucleotide primer UBC-41 generated a fragment of approximately $1300 \mathrm{pb}$ in size, specifically for the mango flower malformation fungus (Fusarium subglutinans). Since standard RAPD banding patterns are not considered reliable because of their low results of reproducibility, the distinctive fragment was eluted off the agarose gel, purified, cloned and then sequenced. The nucleotide sequences were used to identify and also to synthesize four pairs of specific oligonucleotide named herein Fs 5, Fs 13, Fs 14 and Fs 15. Other Fusarium spp. DNAs sampled from other hosts (garlic, peanut, sugarcane, cyclamen, pea, melon and wheat), from a healthy mango tree cv. Tommy Atkins and other six isolates from symptomatic mango plants were submitted to PCR amplification with these pairs of oligonucleotide. Only fragments from the mango tree fungus Fusarium subglutinans were visualized, showing this way the SCAR oligonucleotide specificity.
\end{abstract}

Index Terms: primers, Mangifera indica, molecular markers, RAPD-PCR.

\section{INTRODUÇÃO}

Dentre as doenças da mangueira (Mangifera indica L.), a malformação destaca-se por causar grandes prejuízos em países produtores da fruta. O principal sintoma dessa doença é a deformação floral, caracterizada pelo embonecamento de ramos vegetativos e panículas florais devido à superbrotação das gemas, que formam uma massa de flores e/ou brotos que não produzem frutos (Kumar et al., 1993). Outros sintomas importantes dessa doença são a deformação de árvores maduras e a infecção em mudas, que facilitam a propagação da malformação da mangueira para novas áreas (Kumar et al., 1993; Ploetz, 1994).

Fusarium subglutinans Wollenweb \& Reinking (Ploetz, 1994) é reconhecido como o agente causal da malformação da mangueira. Esta espécie forma parte de um complexo com isolados de Giberella fujikuroi e está também associada com outros isolados de Fusarium spp. de vários hospedeiros, previamente reportados (Steenkamp et al., 2000a). Entre esses hospedeiros, destacam-se culturas economicamente importantes, como arroz (Oryza sativa), milho (Zea mays), trigo (Triticum aestivum), sorgo

\footnotetext{
(Trabalho 015-07). Recebido em 03-01-2007. Aceito para publicação em : 20-07-2007. Parte da tese de Doutorado do primeiro autor. Bolsista da FAPESP. ${ }^{2}$ Departamento de Produção Vegetal, Faculdade de Ciências Agrárias e Veterinárias, Universidade Estadual Paulista, Campus de Jaboticabal, Via de Acesso Prof. Paulo Donato Castellane s/n, CEP:14884-900, Jaboticabal, SP, Brasil, e-mail: rzaccaro@fcav.unesp.br.

${ }^{3}$ Departamento de Tecnologia, Faculdade de Ciências Agrárias e Veterinárias, Universidade Estadual Paulista, Campus de Jaboticabal, Via de Acesso Prof. Paulo Donato Castellane s/n, CEP:14884-900, Jaboticabal, SP, Brasil, e-mail: egerle@fcav.unesp.br.
} 
(Sorghum bicolor), manga (Mangifera indica), pínus (Pinus spp.), aspargo (Asparagus officinalis), abacaxi (Ananas comosus), figo (Ficus carica), ameixa (Prunus spp.), cana-de-açúcar (Saccharum officinarum), amendoim (Arachis hypogaea), ervilha (Pisum sativum), melão (Cucumis melo), alho (Allium cepa) e ciclâmen (Cyclamen persica) (Kumar et al., 1993).

De acordo com Steenkamp et al. (2000a), é pouco precisa a diferenciação dos Fusarium spp. de diferentes hospedeiros somente por caracterização morfológica, devido a sua grande similaridade. Uma das alternativas encontradas para solucionar o problema é a utilização de técnicas moleculares, mais eficientes por acessar diretamente o DNA, tornando-se mais eficiente na discriminação dos fungos. Entre as técnicas moleculares utilizadas para discriminação de Fusarium spp. destacam-se: Polimorfismo de DNA amplificado ao acaso (RAPD) (Duteau \& Leslie, 1991; Ouellet \& Seifert, 1993; Voigt et al., 1995; Viljoen et al., 1997), Polimorfismo no comprimento de fragmentos de restrição (RFLP) (Correll et al., 1992; Nicholson et al., 1993), espaços intergênicos transcritos (ITS 1 e ITS 2) (O’Donnell \& Cigelnik, 1997; Waalwijk et al., 1996) e dados de seqüências gênicas conservadas (Steenkamp et al., 2000a), Polimorfismo no comprimento de fragmentos amplificados (AFLP) (Jurgenson et al., 2002) e Reação de Polimerase em Cadeia (PCR) (Hue et al., 1999; Steenkamp et al., 2000b).

Steenpkamp et al. (1999) combinaram as técnicas de PCRRFLP para a diferenciação dos fungos de $F$. subglutinans associados a vários hospedeiros (cana-de-açúcar, pinheiro, mangueira e milho). Seus resultados e os obtidos por O'Donnell \& Cigelnik (1997) indicaram que o F. subglutinans está mais fortemente relacionado com a malformação da mangueira do que com os outros hospedeiros.

Marcadores RAPD são ferramentas úteis em virtude de sua facilidade de utilização, rapidez, pouco custo e por utilizar pequenas quantidades de reagentes. Entretanto, esses marcadores são usualmente dominantes e sensíveis a pequenas alterações das condições de amplificação, tendo, assim, baixa reprodutibilidade, além de outras desvantagens, como ambigüidade na interpretação das bandas e co-migração de fragmentos de igual tamanho (Ferreira \& Grattapaglia, 1998). Para aumentar a confiabilidade desses marcadores e convertê-los em marcadores co-dominantes, Paran \& Michelmore (1993) desenvolveram os marcadores SCAR (Região amplificada de seqüência caracterizada). Marcadores SCAR são derivados de marcas RAPD pelo desenvolvimento de oligonucleotídeos maiores. Após a seleção da marca RAPD, o fragmento é clonado e seqüenciado, e é sintetizado um par de oligonucleotídeos de aproximadamente 24 pares de bases. Esses oligonucleotídeos SCAR são utilizados para amplificar as regiões específicas do DNA genômico. Marcadores RAPD foram convertidos em marcadores SCAR por Weng et al. (1998) para comprovar a segregação mendeliana do caráter resistência a doenças. Travensolo (2000) relatou a eficiência de marcadores SCAR em discriminar isolados de Xylella fastidiosa de videira (Vitis vinifera) de outros hospedeiros.

Este trabalho teve por objetivo identificar, através de marcadores RAPD, uma marca específica que pudesse ser convertida em um marcador SCAR, capaz de diferenciar o isolado de F. subglutinans dos isolados de Fusarium spp. de outros hospedeiros.

\section{MATERIAL E MÉTODOS}

\section{Isolados de Fusarium spp. e extração do DNA genômico.}

Foram utilizados oito isolados para o estudo de diversidade genética e obtenção das bandas diferenciais para a construção do marcador SCAR, incluindo um isolado Fusarium subglutinans de mangueira e sete isolados de Fusarium spp. obtidos de plantas hospedeiras de diferentes espécies, provenientes da Micoteca da FCA-UNESP-Câmpus de Botucatu, identificadas como: CICL1975 (ciclamen), AM-128 (amendoim), ERV-1986 (ervilha), CN-243 (cana-de-açúcar), TR-208 (trigo), Me-2690 (melão) e ALL-2066-2 (alho). Cinco isolados adicionais de $F$. subglutinans foram obtidos de plantas de mangueira sintomáticas, cultivados e caracterizados morfologicamente em placas de Petri contendo meio BDA, no Departamento de Fitopatologia da FCAV/UNESP/Jaboticabal. A caracterização morfológica permitiu a identificação do isolado utilizado na caracterização molecular por RAPD e dos cinco isolados adicionais provenientes de mangueira como $F$. subglutinans de acordo com a chave de classificação de Ventura (2000). Isolados de Guignardia spp. e Colletotrichum spp. também foram isolados em mangueira para serem utilizados como controle para a obtenção do marcador específico SCAR. Para a extração do DNA das amostras de Fusarium spp., Guignardia spp. e Colletotrichum spp., foi utilizada a metodologia proposta por Moller et al. (1992). A quantificação do DNA foi realizada em espectrofotômetro, medindo-se a absorbância no comprimento de onda de 260 e $280 \mathrm{~nm}$.

\section{Amplificação do DNA genômico (RAPD-PCR)}

A reação de amplificação do DNA genômico foi ajustada para um volume final de $20 \mu \mathrm{L}$, contendo $30 \mathrm{ng}$ de DNA, tampão de PCR 1X (50 mM KCl, 200 mM Tris-HCl, pH 8,4) (Invitrogen, CA, USA), $1,5 \mathrm{mM} \mathrm{MgCl}_{2}$ (Invitrogen, CA, USA), $200 \mu \mathrm{M} \mathrm{dNTP}$ (Invitrogen, CA, USA), 1,5 U Taq DNA polimerase (Invitrogen, CA, USA), 30 ng de oligonucleotídeo iniciador (UBC - University British Columbia, Vancouver, BC, Canadá) e água pura estéril para completar o volume. As reações foram realizadas em termociclador (PTC 100 Programable Thermal Controler, MJ Research, Inc.) e amplificadas, utilizando-se o seguinte programa: $92^{\circ} \mathrm{C}$ por $3 \mathrm{~min}$, 47 ciclos $\left(92^{\circ} \mathrm{C}\right.$ por $1 \mathrm{~min}, 36^{\circ} \mathrm{C}$ por $1 \mathrm{~min} \mathrm{e} 45 \mathrm{~s} \mathrm{e} 72^{\circ} \mathrm{C}$ por $\left.2 \mathrm{~min}\right)$, $72^{\circ} \mathrm{C}$ por 7 min para desnaturação, pareamento e extensão e um ciclo final a $5^{\circ} \mathrm{C}$. Os produtos de amplificação foram separados por eletroforese em tampão TBE 1X (89 mM Tris; 89 mM Ácido Bórico; 2,5 mM EDTA, pH 8,3), utilizando géis de agarose a 1,5\%, contendo brometo de etídeo $(0,5 \mathrm{mg} / \mathrm{mL})$. O marcador "DNA ladder" de $1 \mathrm{~kb}$ (Invitrogen, CA, USA) foi utilizado como padrão de tamanho molecular, e a visualização dos fragmentos foi realizada sob luz ultravioleta utilizando equipamento de fotodocumentação Gel-Doc 1000 (BioRad, CA, USA).

Purificação do fragmento, clonagem e seqüenciamento. $O$ fragmento de DNA diferencial de F. subglutinans (1300 
pb), obtido da amplificação com o oligonucleotídeo UBC-41, foi eluído do gel de agarose e purificado segundo o protocolo de extração rápida do gel (Rapid Gel Extraction Protocol - Invitrogen, CA, USA). O DNA purificado foi clonado em vetor pUC 18, utilizando o kit Ready-to-Go (Amersham Bioscience); e o plasmídeo, inserido em células competentes de Escherichia coli DH5 $\alpha$. Após a extração plasmidial, o inserto foi seqüenciado, utilizando o kit DNA Sequencing Big Dye Terminator (PE Applied Biosystems, CA, USA): $300 \mathrm{ng}$ do produto amplificado, $2 \mathrm{~mL}$ de BigDye Terminater (PEApplied Biosystems, CA, USA), 3,2 pmoles dos oligonucleotídeos $\mathrm{F} / \mathrm{R}$ utilizados separadamente, $2 \mathrm{~mL}$ de Tampão 5X (400 mM Tris- $\mathrm{HCl}, \mathrm{pH} 9,0,10 \mathrm{mM} \mathrm{MgCl}_{2}$ ), água milliQ filtrada para completar o volume de $10 \mathrm{~mL}$ de reação. O programa para a PCR de seqüenciamento foi composto dos seguintes ciclos: 1 ciclo a $96^{\circ} \mathrm{C}$ por $2 \mathrm{~min} ; 39$ ciclos $\left(96^{\circ} \mathrm{C}\right.$ por $10 \mathrm{~s} ; 52^{\circ} \mathrm{C}$ por $20 \mathrm{~s}$, e 4 min a $60^{\circ} \mathrm{C}$ ) com um ciclo final de $10^{\circ} \mathrm{C}$. O fragmento de DNA amplificado foi precipitado e submetido à eletroforese de seqüenciamento em um equipamento ABI PRISM ${ }^{\mathrm{TM}} 377$ (PE Applied Biosystems, CA, USA).

\section{Desenho dos oligonucleotídeos e amplificação SCAR.}

As sequiências clonadas foram analisadas pelo Programa Sequencing Analysis 3.4, e a qualidade das bases dos cromatogramas, pelo Programa Phred/Phrap/Consed (Gordon et al., 1998). Quatro pares de oligonucleotídeos iniciadores de 19 a $21 \mathrm{pb}$ foram desenhados utilizando o programa OLIGO 4.0 (Rychlik \& Rhoads, 1989) e sintetizados pela BIOSYNTHESIS, Inc. As amplificações SCAR foram realizadas com os DNAs dos fungos Fusarium spp. e da cultivar Tommy Atkins sem sintomas de malformação. A avaliação da especificidade dos oligonucleotídeos SCAR, obtidos para $F$. subglutinans, foi realizada utilizando-se do DNA de três diferentes isolados de Colletotrichum spp. e quatro isolados de Guignardia spp. Cabe ressaltar que esses fungos foram também isolados em mangueira. Também foram utilizados para testar a especificidade dos oligonucleotídeos, os DNAs de outros cinco isolados de F. subglutinans obtidos de plantas de mangueira sintomáticas. As reações de amplificação foram realizadas utilizando $50 \mathrm{ng}$ de cada DNA em volume final de $20 \mathrm{~mL}$, contendo tampão de PCR 1X (Invitrogen, CA, USA), 2 mM $\mathrm{MgCl}_{2}$ (Invitrogen, CA, USA), $200 \mathrm{mM}$ dNTP (Invitrogen, CA, USA), 1,5 U Taq DNA polimerase (Invitrogen, CA, USA) e $30 \mathrm{ng}$ de oligonucleotídeo SCAR sintetizado. A amplificação foi realizada nas mesmas condições descritas anteriormente, exceto nas temperaturas de pareamento de $55 ; 58 ; 60$ e $62^{\circ} \mathrm{C}$ para os oligonucleotídeos $5 \mathrm{Fs}$; $13 \mathrm{Fs}$; $14 \mathrm{Fs}$ e $15 \mathrm{Fs}$. Os produtos foram visualizados e fotografados como descritos anteriormente.

\section{RESULTADOS E DISCUSSÃO}

\section{Identificação do marcador para $F$. subglutinans.}

Vinte oligonucleotídeos randômicos foram testados, pela técnica de RAPD-PCR, sendo que destes somente oito amplificaram o DNA do fungo Fusarium subglutinans (UBC 41; UBC 42; UBC 52; UBC 206; UBC 207; UBC 214; UBC 217 e UBC 227) (Tabela 1). Devido ao fato de os marcadores RAPDs serem sensíveis às condições de amplificação e a diferentes padrões genômicos, houve a necessidade da construção de oligonucleotídeos específicos para o isolado da malformação da mangueira. Desses oito oligonucleotídeos, sete amplificaram o isolado, mas não foi verificada a presença de um fragmento diferencial para o isolado F. subglutinans que pudesse ser utilizado para a construção de marcador SCAR. Assim, foi observado um fragmento diferencial de $1.300 \mathrm{pb}$ somente para o isolado de F. subglutinans quando amplificado com o oligonucleotídeo UBC 41 (Figura 1). O DNA da manga Tommy Atkins, sem problema de malformação, foi utilizado neste trabalho para evitar-se que, ao selecionar o fragmento que serviria de molde para o desenho dos oligonucleotídeos, o mesmo também estivesse presente no DNA da mangueira. Futuramente, pretende-se utilizar os oligonucleotídeos desenhados para identificar o fungo em plantas assintomáticas, ou seja, para assegurar a sanidade de mudas em relação à malformação da mangueira.

\section{Conversão do marcador RAPD em SCAR.}

$O$ fragmento de $1.300 \mathrm{pb}$, amplificado com o oligonucleotídeo UBC 41, foi eluído, inserido no vetor, clonado em $E$. coli e seqüenciado. Após o seqüenciamento do fragmento de interesse, quatro seqüências de aproximadamente $1.300 \mathrm{pb}$ foram utilizadas para o desenho dos oligonucleotídeos.Uma vez que a separação foi realizada por eletroforese em gel de agarose, cujo princípio é a separação através de gradiente de tamanho molecular, provavelmente as quatro seqüências possuíam um tamanho molecular semelhante. Rebouças \& Gomes (1999) ressaltam que é possível obter-se mais de uma seqüência de oligonucleotídeos quando se realiza a eluição de um fragmento de interesse. Os mesmos autores verificaram que, após o seqüenciamento de cerca de 140 plasmídeos recombinantes, foram identificadas 39 seqüências homólogas diferentes de cDNA, encontradas no GenBank.

As seqüências-consenso obtidas para $F$. subglutinans foram avaliadas quanto à similaridade com outros microrganismos, através de ferramenta BLAST (Altschul et al., 1997), junto ao GenBank (http://www.ncbi.nlm.nih.gov/BLAST), sendo que a maior similaridade obtida foi com o fungo Neurospora crassa. As quatro seqüências obtidas para o desenho de pares de oligonucleotídeos foram submetidas ao programa OLIGO 4.0, levando-se como referência as características de menor quantidade de dímeros; menor ocorrência de autopareamento dos oligonucleotídeos, boa relação de bases CG $(75 \%)$; temperatura de pareamento em torno de $60^{\circ} \mathrm{C}$ e número de bases ao redor de 20, consideradas como ideais para a síntese de oligonucleotídeos. Através dos parâmetros requeridos, quatro pares de oligonucleotídeos foram desenhados e sintetizados (Tabela 2), para um tamanho de fragmento esperado de cerca de $1.300 \mathrm{pb}$.

\section{Amplificação dos DNAs por oligonucleotídeos SCAR.}

DNAs genômicos da cv. Tommy Atkins sem inoculação e do fungo $F$. subglutinans foram utilizados na amplificação por PCR com os quatro oligonucleotídeos SCAR (5Fs, 13Fs, 14Fs e 15Fs). No caso dos SCAR desenhados e utilizando a temperatura de pareamento de $62^{\circ} \mathrm{C}$, fragmentos de tamanhos moleculares aproximados ao progenitor (UBC 41) foram observados somente 
para o fungo F. subglutinans (Figura 2). Os marcadores SCAR mantêm as características funcionais do marcador RAPD, possibilitando aumentar sua confiabilidade e também sua repetibilidade entre diferentes laboratórios e espécies. Além disso, tais marcadores mantêm a amplificação do fragmento único, sem alterar o tamanho original no RAPD (Scotti et al., 1998). Outra característica importante é que o polimorfismo que foi detectado na análise de RAPD por UBC 41 para o fungo, não pôde ser observado com os oligonucleotídeos SCAR sintetizados.

\section{Especificidade dos oligonucleotídeos SCAR.}

Foi observado que os quatro pares de oligonucleotídeos originavam apenas um fragmento amplificado após a PCR com o DNA do F. subglutinans. A avaliação da especificidade destes oligonucleotídeos mostrou que apenas os isolados de $F$. subglutinans foram amplificados. Nas Figura 3A, 3B, 3C e 3D, pode-se observar que estes quatro pares de oligonucleotídeos são específicos para os seis isolados de $F$. subglutinans, uma vez que apenas para estes se obteve o fragmento de DNA com cerca de $1.300 \mathrm{pb}$ esperado. Apenas o primer Fs 15 apresentou um fragmento de tamanho menor, de cerca de $950 \mathrm{pb}$. Os demais apresentaram fragmentos com o tamanho esperado. Os quatro pares de SCAR também não amplificaram o DNA dos isolados de Colletotrichum e Guignardia utilizados para testar sua especificidade (todos mostraram a mesma especificidade e estão representados por Fs 5 na Figura 4). Assim, qualquer um desses oligonucleotídeos poderá ser utilizado na identificação do fungo F. subglutinans causador da malformação da mangueira.

Resultado semelhante foi obtido por Hittalmani et al. (1995), quando examinaram a acurácia de marcadores SCAR na identificação de plantas de arroz com gene de resistência ao acamamento. Esses autores verificaram que a identificação dessas plantas com um único oligonucleotídeo foi de $97 \%$, e com a utilização do par de oligonucleotídeos (Forward e Reverse), a sua identificação foi de $100 \%$.

As reações com os quatro pares de oligonucleotídeos desenhados para a identificação do $F$. subglutinans foram realizadas várias vezes, sendo que os resultados apresentaram repetibilidade, comprovando uma das características dos marcadores SCAR. Hittalmani et al. (1995) ressaltaram que os resultados obtidos com marcadores SCAR foram reprodutíveis e podiam ser facilmente visualizados, desde que fossem estreitamente ligados com o lócus de interesse, e a genotipagem de indivíduos para a seleção usando estes marcadores SCAR fosse acurada e eficiente.
TABELA 1 - Relação dos oligonucleotídeos iniciadores utilizados para análise de RAPD, com suas respectivas seqüências.

\begin{tabular}{cc}
\hline Oligonucleotídeos testados & Seqüência dos oligonucleotídeos \\
\hline UBC 036 & CCCCCCTTAC \\
UBC 037 & CCGGGGTTTT \\
UBC 039 & TTAACCGGGC \\
UBC 041 & TTAACCGGGG \\
UBC 042 & TTAACCCGGC \\
UBC 052 & TTCCCGGAGC \\
UBC 053 & CTCCCTGAGC \\
UBC 201 & CTGGGGATTT \\
UBC 206 & GAGGACGTCC \\
UBC 207 & CATATCAGGG \\
UBC 214 & CATGTGCTTG \\
UBC 216 & CATAGACTCC \\
UBC 217 & ACAGGTAGAC \\
UBC 221 & CCCGTCAATA \\
UBC 227 & CTAGAGGTCC \\
UBC 228 & GCTGGGCCGA \\
UBC 229 & CCACCCAGAG \\
UBC 233 & CTATGCGCGC \\
UBC 234 & TCCACGGACG \\
UBC 249 & GCATCTACCG \\
\hline
\end{tabular}

TABELA 2.-Seqüência nucleotídica, tamanho e temperatura de pareamento dos oligonucleotídeos SCAR.

\begin{tabular}{cccc}
\hline \multirow{2}{*}{ SCAR } & Sequência dos oligonucleotídeos & Tamanho $\mathbf{( p b )}$ & Tm $(\mathbf{C})$ \\
\hline $5 \mathrm{Fs}$ & GGGCCACTATGAGAAGTAAG & 20 & 60 \\
& TGGGGTGGAAAGAAGACTC & 18 & 58 \\
\multirow{2}{*}{$13 \mathrm{Fs}$} & CCGGGGTCTCAAGTGTGAC & 19 & 62 \\
& GGCCCTGGCTTCGGTGATA & 19 & 62 \\
$14 \mathrm{Fs}$ & GCGGCGAGGGGTGGAACTA & 19 & 64 \\
& CGGCACCTCTTTTACCTGTTA & 21 & 62 \\
$15 \mathrm{Fs}$ & GCGCCAGTAACACGTACCAC & 20 & 64 \\
& GGCGAAACCATCCATGTGAC & 20 & 62 \\
\hline
\end{tabular}

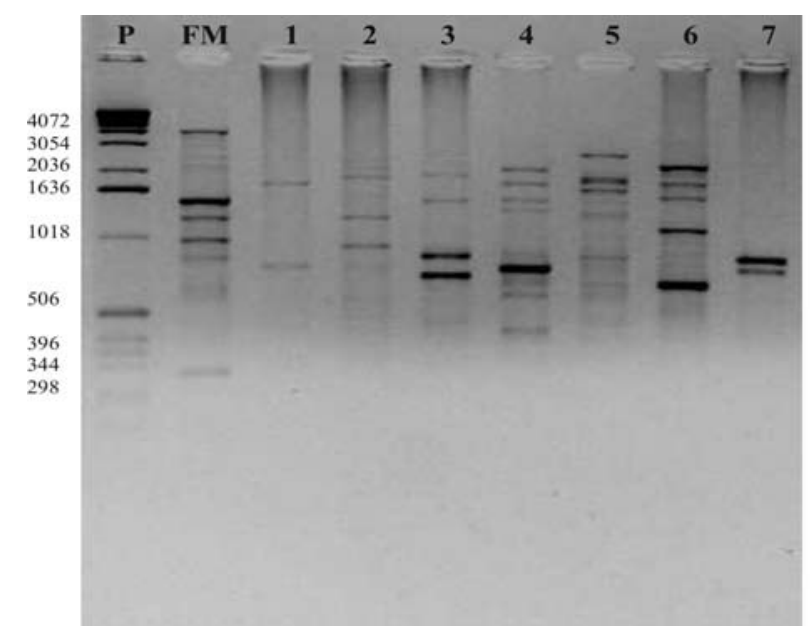

FIGURA 1 - Perfil do produto amplificado do DNA do fungo Fusarium subglutinans e de sete isolados de Fusarium spp. com o oligonucleotídeo UBC 41. P: Padrão de tamanho molecular de $1 \mathrm{~kb}$ (Invitrogen, CA, USA); FM: F. subglutinans; 1: CICL-1975, 2: AM-128; 3: ERV-1986; 4: CN-243; 5: TR-208; 6: Me2690 e 7: ALL-2066-2. 

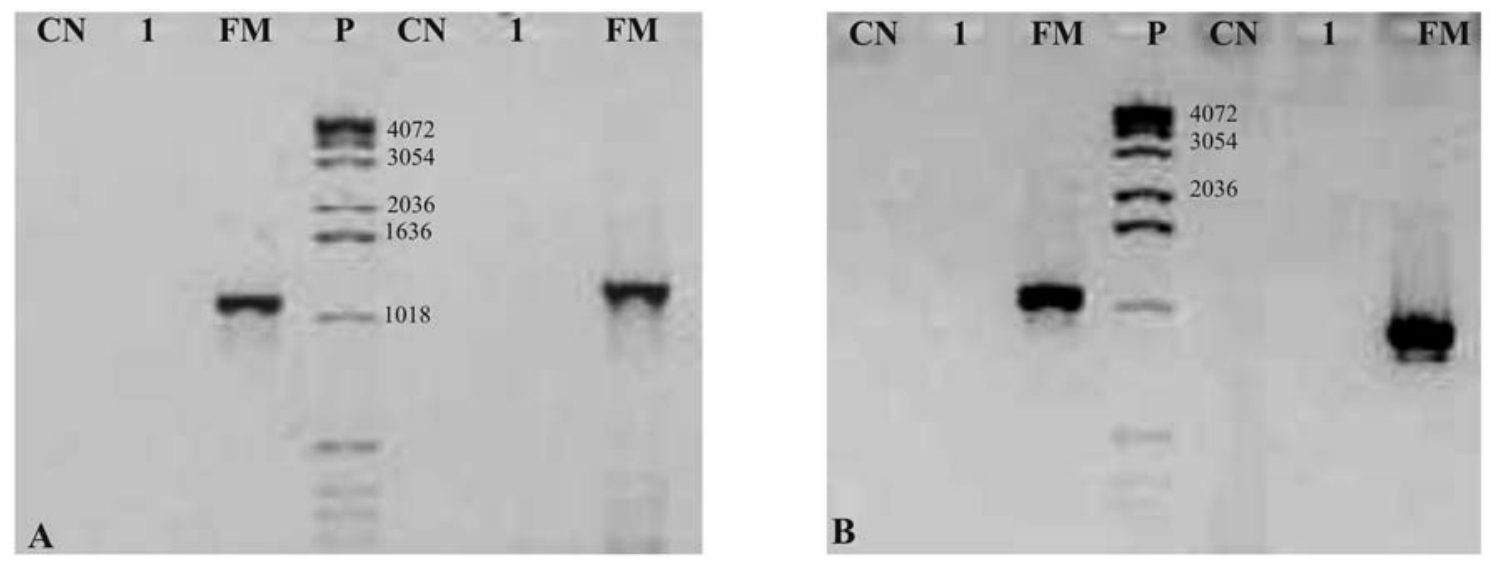

FIGURA 2 - Perfil eletroforético apresentado pela amplificação do DNA do fungo e da mangueira, com quatro oligonucleotídeos específicos para Fusarium subglutinans. CN: Controle Negativo; 1: cultivar Tommy Atkins; FM: F. subglutinans; P: Padrão de tamanho molecular de $1 \mathrm{~kb}$ (Invitrogen, CA, USA). A Figura 2A: amplificação com os pares de oligonucleotídeos 5Fs e 13Fs e Figura 2B com 14Fs e 15Fs.

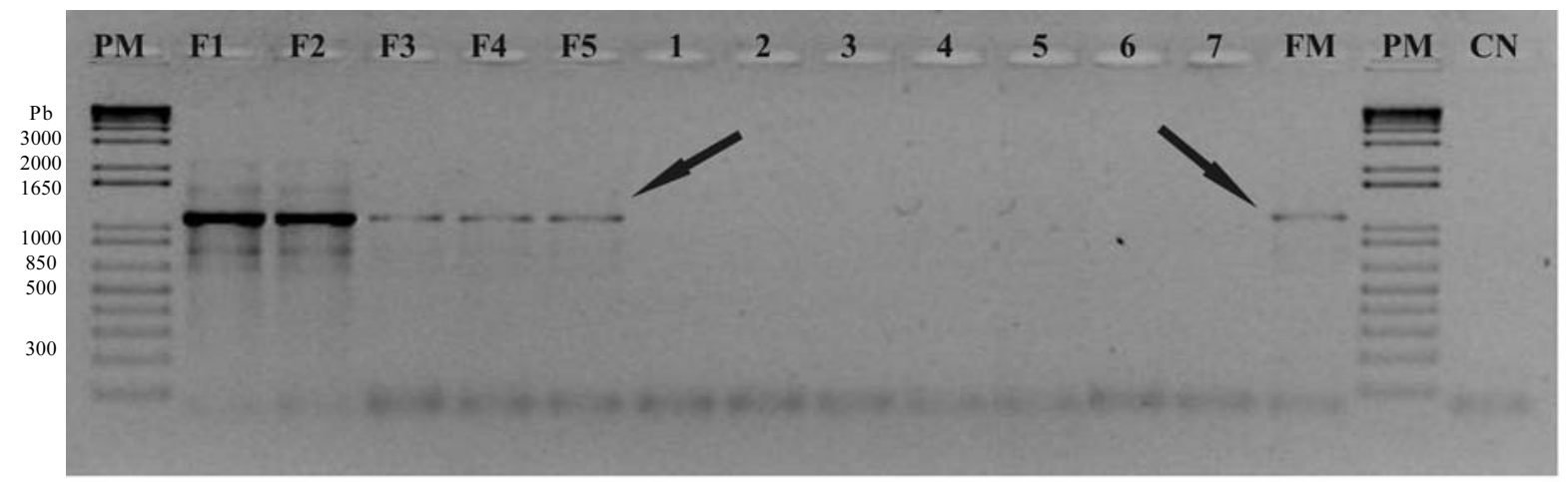

FIGURA 3A - Perfil do produto de amplificação do DNA do fungo Fusarium subglutinans isolados de mangueira (F1 a F5) e dos sete isolados de Fusarium spp. de diferentes hospedeiros (1 a 7), com o oligonucleotídeo Fs 5. P: Padrão de tamanho molecular de 1 Kb Plus (Invitrogen, CA, USA); CN: Controle Negativo; 1: CICL-1975, 2: AM-128; 3: ERV-1986; 4: CN-243; 5: TR-208; 6: Me-2690 e 7: ALL-2066-2; FM: F. subglutinans utilizado para selecionar a banda SCAR.

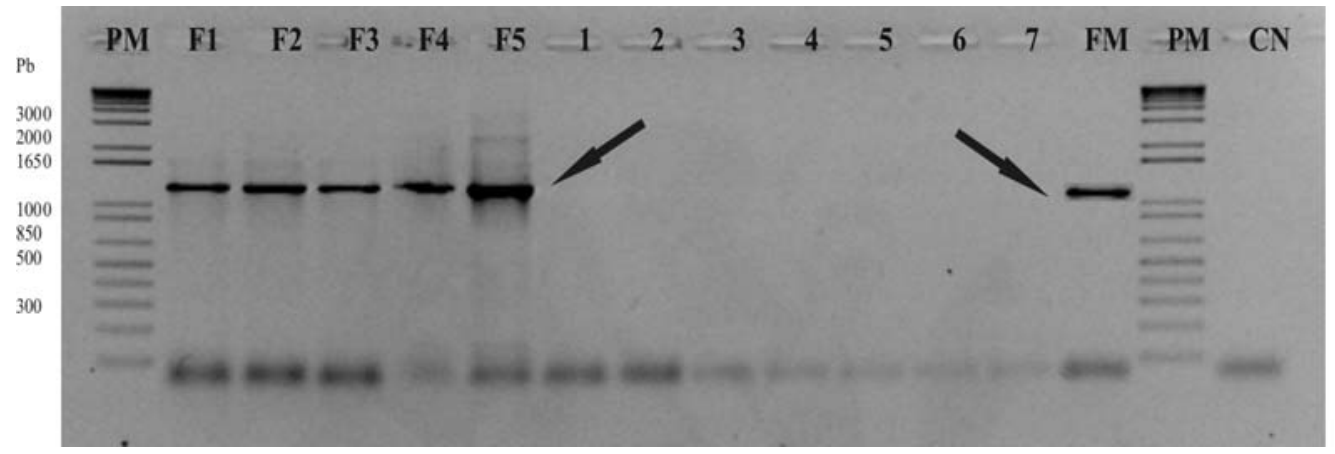

FIGURA 3B- Perfil do produto de amplificação do DNA do fungo Fusarium subglutinans isolados de mangueira (F1 a F5) e dos sete isolados de Fusarium spp. de diferentes hospedeiros (1 a 7), com o oligonucleotídeo Fs 13. P: Padrão de tamanho molecular de 1 Kb Plus (Invitrogen, CA, USA); CN: Controle Negativo; 1: CICL-1975, 2: AM-128; 3: ERV-1986; 4: CN-243; 5: TR-208; 6: Me-2690 e 7: ALL-2066-2; FM: F. subglutinans utilizado para selecionar a banda SCAR. 


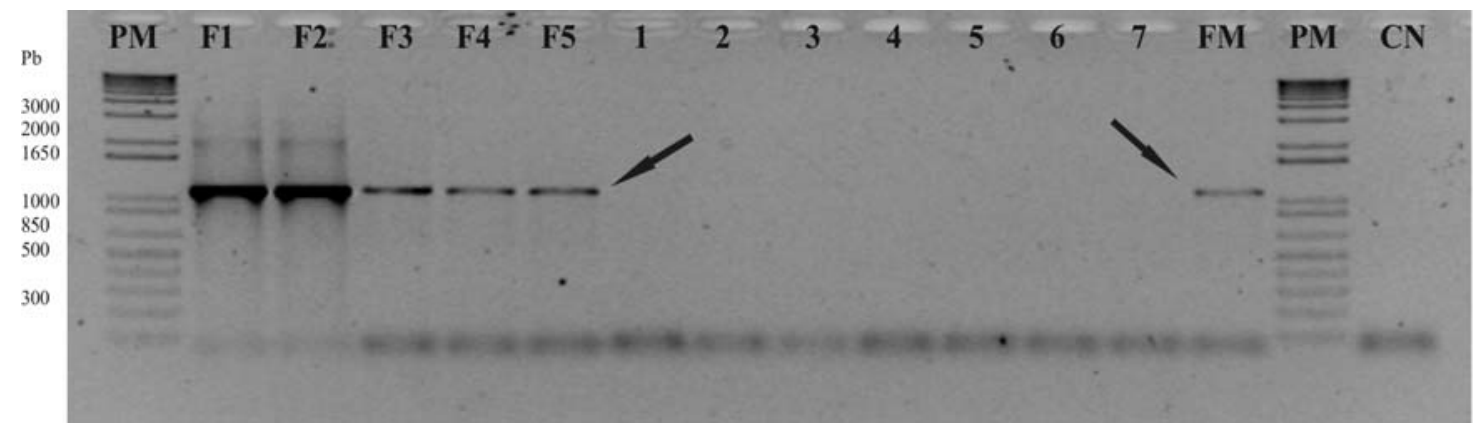

FIGURA 3C - Perfil do produto de amplificação do DNA do fungo Fusarium subglutinans isolados de mangueira (F1 a F5) e dos sete isolados de Fusarium spp. de diferentes hospedeiros (1 a 7), com o oligonucleotídeo Fs 14. P: Padrão de tamanho molecular de 1 Kb Plus (Invitrogen, CA, USA); CN: Controle Negativo; 1: CICL-1975, 2: AM-128; 3: ERV-1986; 4: CN-243; 5: TR-208; 6: Me-2690 e 7: ALL-2066-2; FM: F. subglutinans utilizado para selecionar a banda SCAR.

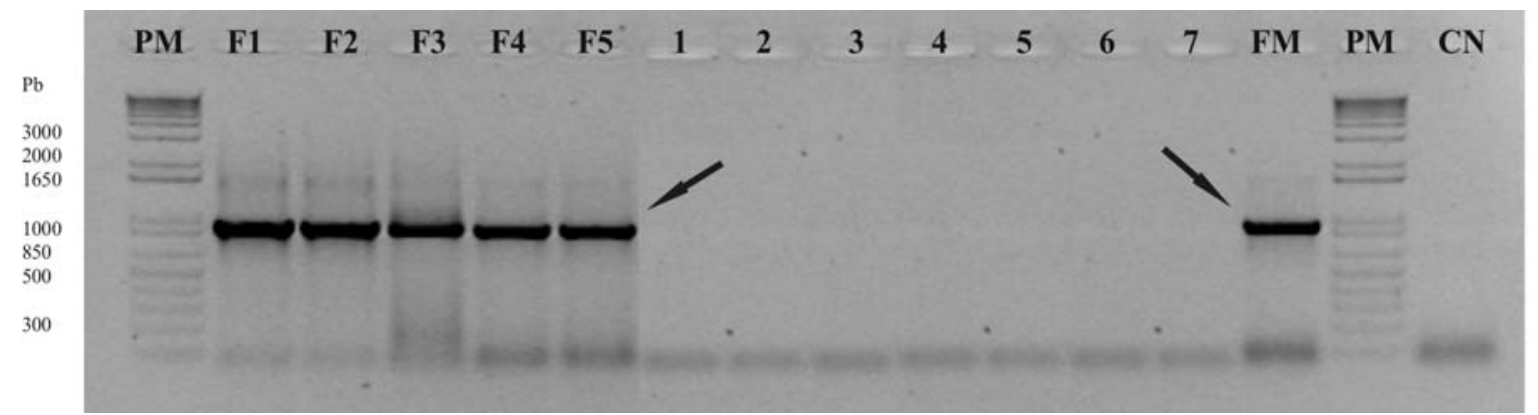

FIGURA 3D - Perfil do produto de amplificação do DNA do fungo Fusarium subglutinans isolados de mangueira (F1 a F5) e dos sete isolados de Fusarium spp. de diferentes hospedeiros (1 a 7), com o oligonucleotídeo Fs 15. P: Padrão de tamanho molecular de 1 Kb Plus (Invitrogen, CA, USA); CN: Controle Negativo; 1: CICL-1975, 2: AM-128; 3: ERV-1986; 4: CN-243; 5: TR-208; 6: Me-2690 e 7: ALL-2066-2; FM: F. subglutinans utilizado para selecionar a banda SCAR.

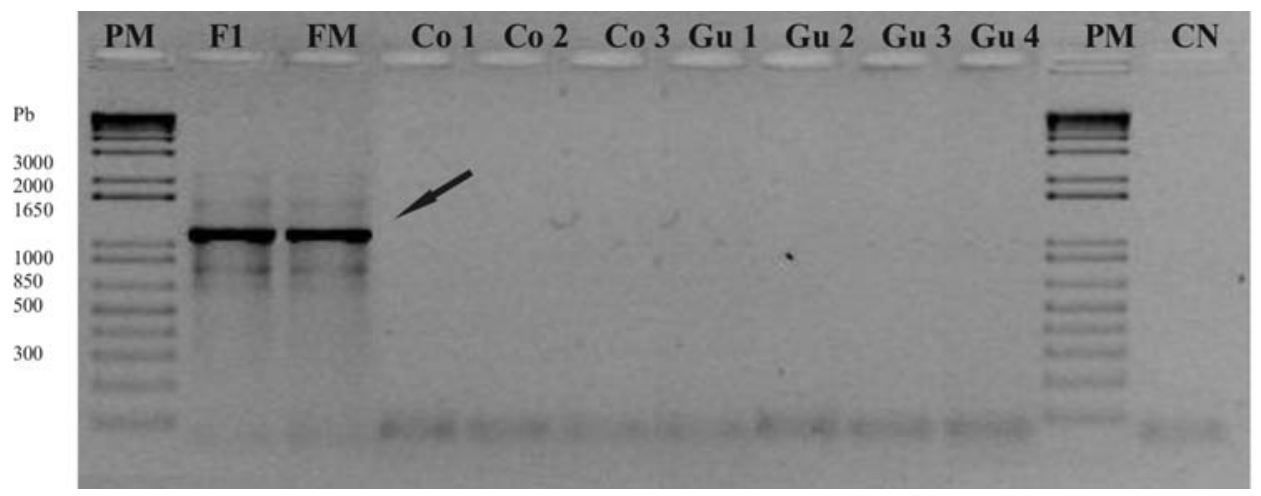

FIGURA 4 - Perfil do produto de amplificação do DNA do fungo F. subglutinans (F1 e FM), apresentando a banda característica, e dos outros fungos também isolados de mangueira, sem a banda, com o oligonucleotídeo Fs 5. P: Padrão de tamanho molecular de $1 \mathrm{~Kb}$ Plus (Invitrogen, CA, USA); Co 1, Co 2 e Co 3: isolados de Colletotrichum spp; Gu 1, Gu 2, Gu 3 e Gu 4: isolados de Guignardia spp.; CN: Controle Negativo. 


\section{CONCLUSÃO}

Os marcadores moleculares desenvolvidos neste trabalho foram úteis na discriminação do fungo $F$. subglutinans da malformação da mangueira dos demais utilizados neste trabalho. A alta diversidade genética de fungos pode ser considerada um entrave para os trabalhos de melhoramento genético e o desenvolvimento de variedades resistentes às doenças, uma vez que populações com grande diversidade genética, como é o caso do gênero Fusarium, são hábeis na quebra de resistência em um curto espaço de tempo. Embora a técnica de SCAR e os resultados obtidos neste trabalho tenham sido utilizados para a discriminação entre F. subglutinans de vários hospedeiros, outras estratégias poderão ser desenvolvidas, como a utilização desses oligonucleotídeos em serviços de quarentena, visando à certificação de mudas sadias de mangueira.

\section{AGRADECIMENTOS}

À Fundação de Amparo à Pesquisa do Estado de São Paulo - FAPESP, pelo suporte financeiro, processo n ${ }^{\circ}$ 98/09851-1.

\section{REFERÊNCIAS}

ALTSCHUL, S.F.; MADDEN, T.L.; SCHÄFFER, A.A.; ZHANG, J.; ZHANG, Z.; MILLER, W.; LIPMAN, D.J. Gapped BLAST and PSI-BLAST: a new generation of protein database search programs. Nucleic Acids Research, Oxford, n.25, p.3389-3402, 1997.

CORRELL, J.C.; GORDON, T.R.; MCCAIN, A.H. Genetics diversity in California and Florida populations of the Pitch Canker Fungus Fusarium subglutinans f. sp. pini. Phytopathology, St. Paul, v.82, n.4, p.415-420, 1992.

DUTEAU, N.M.; LESLIE, J.F. RAPD markers for Gibberelia fujikuroi (Fusarium section Liseola). Fungal Genetics Newsletters, Kansas City, v.38, p.37-40, 1991.

FERREIRA, M.E.; GRATTAPAGLIA, D. Introdução ao uso de marcadores moleculares em análise genética. Brasília: EMBRAPA-CENARGEN, 1998.220p.

GORDON, D.; ABAJIAN, C.; GREEN, P. Consed: A graphical tool for sequence finishing. Genome Research, Toronto, n.8, p.195202,1998 .

HITTALAMANI, S.; FOOLAND, M.R.; MEW, T.; RODRIGUEZ, R.L.; HUANG, N. Development of a PCR-based marker to identify rice blast resistance gene, $\mathrm{Pi}-2(\mathrm{t})$, in a segregating population. Theoretical and Applied Genetics, Berlim, n.91, p. 9-14, 1995.

HUE, F.X.; HUERRE, M.; ROUFFAULT, M.A.; BIEVRE, C. Specific detection of Fusarium species in blood and tissues by a PCR technique. Journal of Clinical Microbiology, Washington, v.37, n.8, p.2434-2438, 1999.

JURGENSON, J.E.; ZELLER, K.A.; LESLIE, J.F. Expanded Genmetric Map of Gibberella moniliforms (Fusarium verticilioides). Applied and Environmental Microbiology, Washington, v.68, n.4, p.1972-1979, 2002.

KUMAR, J.; SINGH, U.S.; BENIWAL, S.P.S. Mango malformation: one hundred years of research. Annual Review of Phytopathology, Palo Alto, v.31, p.217-232, 1993.

MOLLER, E.M.; BAHNWEG, G.; SAMPERMANN, H.; GEIBER, H.H. A simple and efficient protocol for isolation of high molecular weight DNA from filamentous fungi, fruit bodies and infected plant tissues. Nucleic Acids Research, Oxford, v.20, n.22, p.61156116, 1992 .

NICHOLSON, P.; JENKINSON, P.; REZANOOR, H.N.; PARRY, D.W. Restriction fragment length polymorphism analysis of variation in Fusarium species causing ear blight of cereals. Plant Pathology, Palo Alto, v.42, p.905-914, 1993.

O'DONNELL, K.; CIGELNIK, E. Two divergent intragenomic rDNA ITS 2 types within a monophyletic lineage of the fungus Fusarium are non-orthologous. Molecular Phylogenetics Evolution, San Diego, n.7, p. 103-117, 1997.

OULLET, T.; SEIFERT, K.A. Genetic characterization of Fusarium graminearum strings using RAPD and PCR amplification. Phytopathology, St. Paul, v.83, p.1003-1007, 1993.

PARAN, I.; MICHELMORE, R.W. Development of reliable PCRbased markers linked to downy mildew resistance genes in lettuce. Theoretical and Applied Genetics, Berlim, v.85, p.985-993, 1993.

PLOETZ, R.C. Distribution and prevalescence of Fusarium subglutinans in mango trees affected by malformation. Canadian Journal of Botany, Otawa, v.72, p.7-9, 1994.

REBOUÇAS, N.A; GOMES, M.D. Hibridização subtrativa seguida de PCR. Biotecnologia: Ciência e Desenvolvimento, Brasília, v. 11, p.30-35, 1999.

RYCHLIK, W.; RHOADS, R.E. A computer program for choosing optimal oligonucleotides for filter hybridization and in vitro amplification of DNA. Nucleic Acids Research, Oxford, v.17, p.8543-8551, 1989.

SCOTTI, I.; TROGGIO, M.; SORANZO, N.; VENDRAMIN, G.G.; BUCCI, G. A new set of PCR-based, locus-specific markers for Picea abies (L.) Karst. Molecular Ecology, Loughborough, v.7, p.783-785, 1998.

STEENKAMP, E.T; WINGFIELD, B.D; COUTINHO, T.A; WINGFIELD, M.J.; MARASAS, W.F.O. Differention of Fusarium 
subglutinans f.sp. pini by tristone gene sequence data. Applied and Environmental Microbiology, Washington, v.65, n.8, p.3401$3406,1999$.

STEENKAMP, E.T; BRITZ, H.; COUTINHO, T.A; WINGFIELD, B.D; MARASAS, W.F.O.; WINGFIELD, M.J. Molecular characterization of Fusarium subglutinans associated with mango malformation. Molecular Plant Pathology, London, v.1, n.3, p.187193, 2000a.

STEENKAMP, E.T; WINGFIELD, B.D; COUTINHO, T.A;ZELLER, K.A.; WINGFIELD, M.J.; MARASAS, W.F.O.; LESLIE, J.F. PCRbased identification of MAT-1 and MAT-2 in the Gibberella fujikuroi species complex. Applied and Environmental Microbiology, Washington, v.66, n.10, p.4378-4382, 2000b.

TRAVENSOLO, R.T. Marcador SCAR para Xylella fastidiosa em videiras. 2000. 54f. Dissertação (Mestrado em Genética e Melhoramento de Plantas)- Faculdade de Ciências Agrárias e Veterinárias, Universidade Estadual Paulista, Jaboticabal, 2000.
VENTURA, J., A.. Taxonomia de Fusarium e seus segregados. Parte II - chaves para identificação. Revisão anual de Patologia de Plantas, v.8, p.303-338, 2000.

VILJOEN, A.; WINGFIELD, M.J.; MARASAS, W.F.O. Characterization of Fusarium subglutinans f. sp. pini causing root disease of Pinus patula seedlings in South Africa. Mycological Research, Cambridge, n.101, p.437-445, 1997.

VOIGT, K.; SCHLEIER, S.; BRÜCKNER, B. Genetic variability in Gibberella fujikuroi and some related species of the genus Fusarium based on random amplificantion of polymorphic DNA (RAPD). Current Genetics, Göteborg, n.27, p.361-368, 1995.

WAALJWIJK, C.; KONING, J.R.A.; BAAYEN, R.P.; GAMS, W. Discordant groupings of Fusarium spp. from the sections Elegans, Liseola and Dlaminia based on ribossomal ITS 1 and ITS 2 sequences. Mycologia, New York, n.88, p.361-368, 1996.

WENG, C.; KUBISIAK, T.L.; STINE, M. SCAR markers in a longleaf pine x slash pine F1 family. Forest Genetics, Zvolen, v.5, n.4, p.239-247, 1998. 